\title{
Sensory hallucinations in the extended choreographic
}

\author{
Johannes Birringer
}

DAP-Lab, Brunel University London

\begin{abstract}
Deriving its impetus from contemporary associations between the choreographic as extended sculptural (plastic and virtual) scenographies and augmented virtuality, and thus also reimagining some of the radical modernist abstract and technologized poetic techniques invented by Bauhaus artists such as Schlemmer and Moholy-Nagy, this essay mixes up questions of common perception with un-common senses and "homuncular flexibility" (Jaron Lanier). It focusses on kinaesthetic, trans-sensorial notions of material affect in dance-theatre environments where performers or visitors move between real and unreal space. The author briefly discusses examples drawn from atmospheric studies, architecture and choreographic objects, reflecting on the impact of the Bauhaus on the design of such sensorial environments which themselves are conceived as performative, not built-in stable forms. The hallucinatory dimension is introduced in reference to matsutake and forest dance (Anna Lowenhaupt Tsing), and to tactile-aural choreographies in recent productions of the DAP-Lab, the author's production company. The essay imagines more speculative developments of how bodies and matter come to affect, and be affected by, augmented reality and virtual reality interfaces within kinetic atmospheres - here called "kimospheres."
\end{abstract}

\section{The extended choreographic}

To walk attentively through a forest, even a damaged one, is to be caught by the abundance of life: ancient and new; underfoot and reaching into the light. But how does one tell the life of the forest? We might begin by looking for drama and adventure beyond the activities of humans. This is the puzzle [...]: can I show landscape as the protagonist of an adventure in which humans are only one kind of participant? (Tsing 2015, 155)

My introductory epigraph will resonate before long, I believe, once I have walked into the atmospheres of contemporary digital art installations and explored with you the notion of an extended choreographic. This extension reaches far beyond the theatre 
and leaves behind older distinctions between actor, media, things and words. It touches upon current materialist and ecological concerns with contaminated entanglements, as Anna Lowenhaupt Tsing considers them evoking collaboration, gathering, happening, crossing over - something she also calls "interwoven rhythms" (Tsing 2015, 34). In her research, such affective rhythms and entanglements embrace human and natural histories; the particular actor or life form in the assemblages and trajectories she pursues is matsutake, a sought-after mushroom. In our case, the focus is on lemurs and tamarind trees, and on elements of sensory choreography through performative constructions of reality and virtuality - in analogy we might even think of such sensorial habitats as precarious environments.

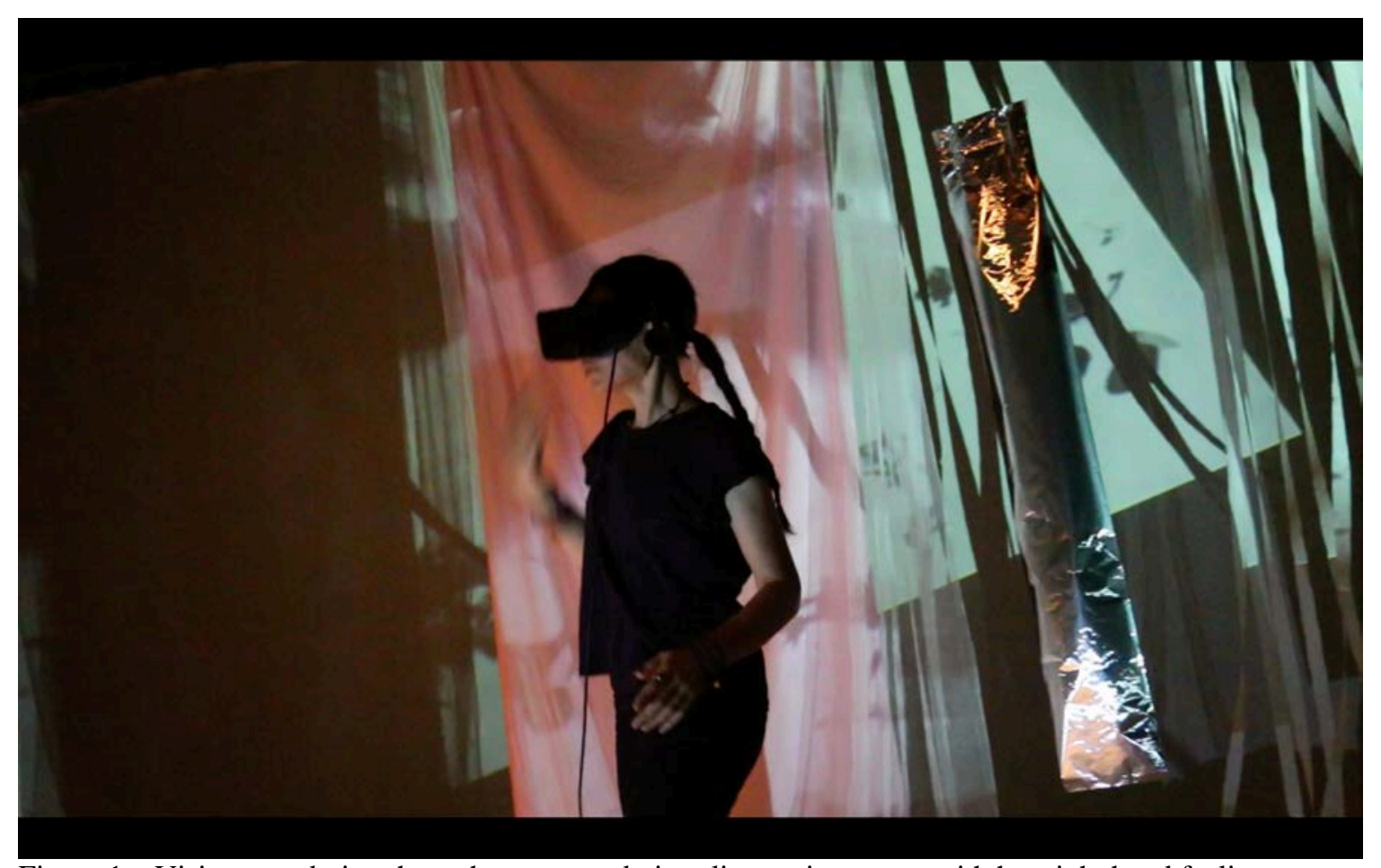

Figure 1. Visitor wandering through augmented virtuality environment, with her right hand feeling imaginary resistance. CNDP Bucharest, 2018 (C) DAP-Lab

The extended choreographic, if we were tracking Rosalind Krauss's notion of the “expanded field” (Krauss 1978), implies not only the sculptural-architectural, but the unhinging of clear sites of artistic forms/practices. It connotes a spiritual kinship with Oskar Schlemmer's sculpturized figurines and the wild growth of his costumes that would spatially and atmospherically embed the human being (as Kunstfigur) into technically designed environment. When I look at some of his bulbous, warped figurines, I think of mushrooms. Schlemmer is a painter and spatial artist, in the 
manner in which I read landscapes by Robert Smithson, James Turrell and Olafur Eliasson, or choreographies by Dimitris Papaioannou, Meredith Monk, Mette Ingvartsen and Yann Marussich. From a large distance (of nearly a hundred years), the Bauhaus objects and living machines may have become less legible. ${ }^{1}$ Yet many of Schlemmer's forays that stimulated me were conducted in movement, in what he referred to as “metaphysical theatre” or “costume ballet” (Schlemmer in Blume 2014, 9) - where the "bodily" shapes and inventions of his "elementary-mathematical forms” (Scheper 1988, 49) dissolved into spatial volumes, and to some extent became dematerialized into abstracted geometries, rhythms, and arrays (shadows and light rays, in the case of the Metalltanz). Here I propose to take the extended choreographic some steps further, positing its virtual and homuncular potential expanding into constricted digital space (virtual reality or virtual environment).

\section{All-body masks and deep-sea divers}

The Bauhaus was foremost an academy for the visual arts, crafts, and architecture/design. Schlemmer's stage workshop therefore may appear to have been peripheral (just as his stone sculpture workshop was), since founder Walter Gropius's experimental model of art education focussed on the development of prototypes to yield industrial commissions, furthering the mix of artistic inventiveness and industrial production. However, Gropius had formulated the new credo, at the 1923 Bauhaus exhibition, as a demonstration of the fusion of art and technology. This proved to be path-breaking and concerns us today. Schlemmer, although not as strongly as Johannes Itten, had a metaphysical mindset and a strong interest in symbolic images, while at the same time exploring the precision logic of technological machinery, "scientific apparatus of glass and metal, the artificial limbs developed by surgery, the fantastic costumes of the deep-sea diver and the modern soldier, and so forth” (Blume 2014, 10).

Schlemmer's stage workshop garnered a particular role in the interlinking of activities, combining art, craftsmanship and play. Schlemmer had worked through painting, wood, stone, and sculpture toward performance - this heterogeneous combination makes sense as a visual-movement art, in its modernist tendency toward abstraction. The Triadic Ballet, the dances for which he is mostly remembered, had 
already been composed between 1916-22 before being presented during the 1923 Bauhaus exhibition. 18 costumes were designed to be performed to correspond to the colors of the three parts (yellow, pink and black series) and encompass a total of twelve scenes (Bilder-Tänze). The costumes are well known from recent exhibitions (e.g. at Barbican Art Gallery 2012; or Human-Space Machine created by the Bauhaus Dessau Foundation in 2015) and have evocative names such as "Sphere Hands," "Round Skirt,” “The Abstract,” "Dancer with Golden Sphere,” "Dancer, Turkish,” “Disc Dancer,” “The Diver,” etc. Schlemmer’s work as a painter and sculptor fundamentally drove his experiments as a choreographer and his continuing concern with space and plasticity (Birringer 2013). The latter, akin with the architectonics Gropius imagined for the Bauhaus building design approaches (interior and exterior design of modern "life processes"), was formulated in the description of the main activities of the stage workshop: the investigation of space, form, color, sound, movement and light (Trimingham 2011, 18).

This scope of investigation drives my reflections on work I collaboratively developed with the DAP-Lab but also observed in other installations and digital art works. ${ }^{2}$ DAP-Lab’s current research links augmented reality and kinetic atmospheres - I call them kimospheres - with forays into Virtual Reality (VR). ${ }^{3}$ These dives into virtual landscapes need to be examined more carefully. There is of course drama beyond the human figure and gestalt thinking so apparently central still to Schlemmer’s concerns. But how can landscape become protagonist? Dance installations as I had understood them over past decades were largely site-specific or geared towards an experience of sensorial or somatic tendencies: dance as physically interactive constellation requiring engagement, deep listening, touch, playful or ritual responses, attention, care, uninhibition. My knowledge of body weather techniques, which are in tune with such deep attention, are owed to butoh training and the Qigong method we practice in our ensemble. Body-Mind Centering and other somatic practices are all directed at embodied perceptions and empathetic senses - in some instances specifically addressing our kinasethetic, tactile and proprioceptive orientation in non-visual space. ${ }^{4}$ The emergence of a more fully digitalized, networked and social media communications world seems to pose challenges to the real-corporeal, and to "being alive” in the sense in which anthropologist Tim Ingold describes interaction and moving with an animic cosmos, with sky, earth and weather $(2011,73)$. Digital, 
computational processes and immersion technologies generate new parameters, reductions and incompatibilities. They engineer new navigations through sensorial rewiring and perceptual adaptation.

In the following, I examine the transporting interfaces with digitally designed mixed reality and virtual realms, observing how wearable digital technologies are integrated or how they become somatic-experiential, and how for example the isolation of the VR headset - similar to the all-body mask of Schlemmer's figurines ${ }^{5}$ - does constrain the wearer's ability to feel real immersion. It does not, however, prevent emotional and embodied connections and proprioceptive sensations. On the contrary, it may enhance dramaturgies of proximal and energetic, and even ecstatic, experience. This is what I want to refer to as the hallucinatory: the design of a virtual environment will shift perceptual fields and generate a new viscosity of sensation through changes and disorientations of the mapping of one's physical body.

\section{Sensory Environments/Choreographic Objects}

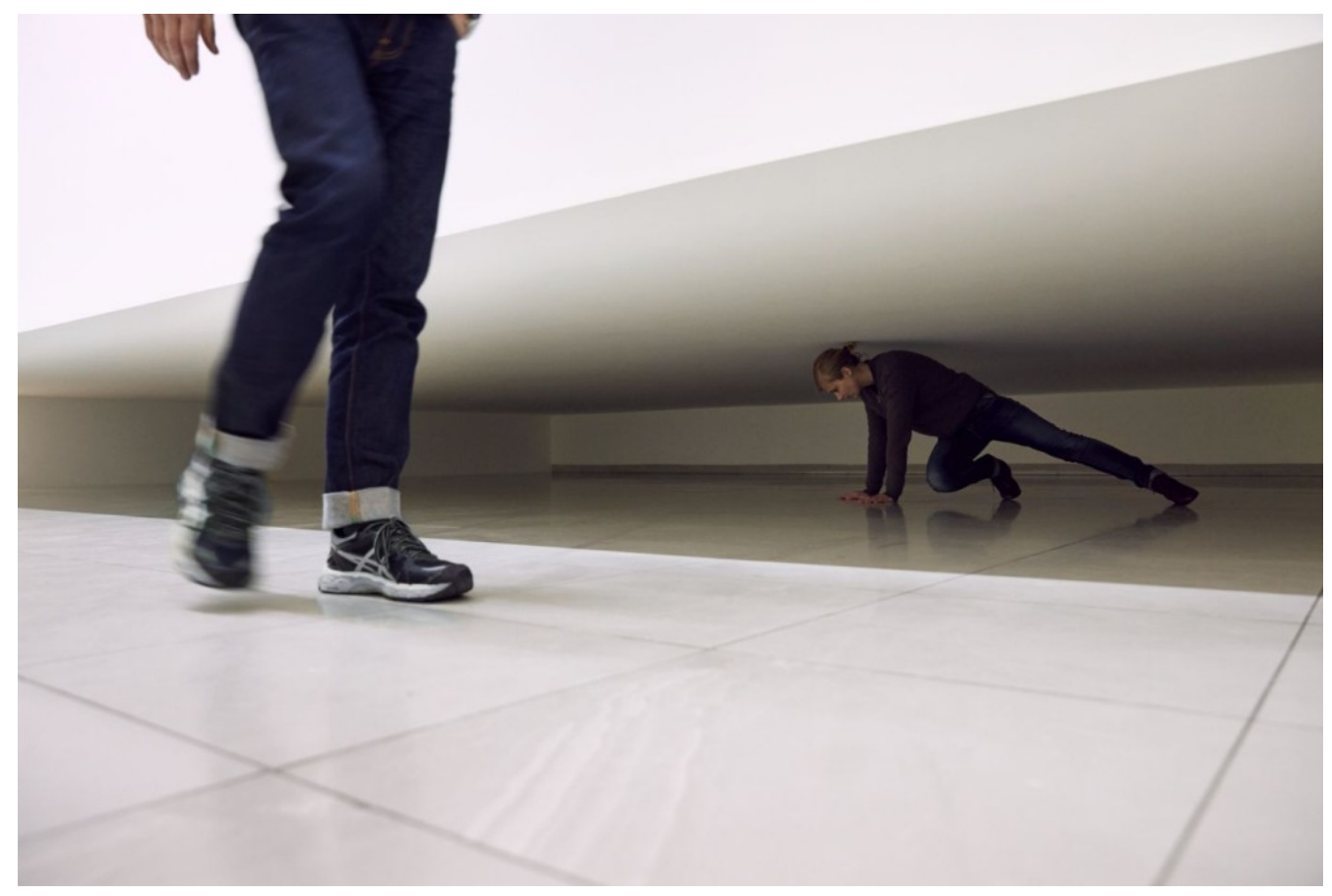

Figure 2. William Forsythe, A Volume, within which it is not Possible for Certain Classes of Action to Arise, 2015, MMK Museum für Moderne Kunst Frankfurt. Photo courtesy of MKK. 
What are we to make of an all-body mask that constrains the wearers or even makes it impossible for them to see what they do? The notion of the costume as mask, given the abstracting, geometric figurations Schlemmer had built as wearable costumesculptures for the Bauhaus dances, invites speculation on how a difficult costume (which hides the face and occludes vision) is meant to make the wearer move, prevent them from moving in any conventional way or compelling them to behave in ways they were not aware of previously. When I began to work with fashion designer Michèle Danjoux and noted encumbrances or challenges she increasingly built into dancers' garments, the performances we developed with the DAP-Lab gained a dimension that resonated with other "choreographic objects” (William Forsythe’s term) created by contemporary dance-theatre artists who moved off the stage. Such installations were often participatory, inviting the audience to inter-act. Yet Danjoux's wearable encumbrance, or the threshold of animation she emplanted (Danjoux 2017), was unlike the spatial or object-oriented approach taken, for example, in Forsythe's $A$ Volume, within which it is not Possible for Certain Classes of Action to Arise (2015) or The Fact of Matter (2009). I will return to the concept of wearable space in a moment.

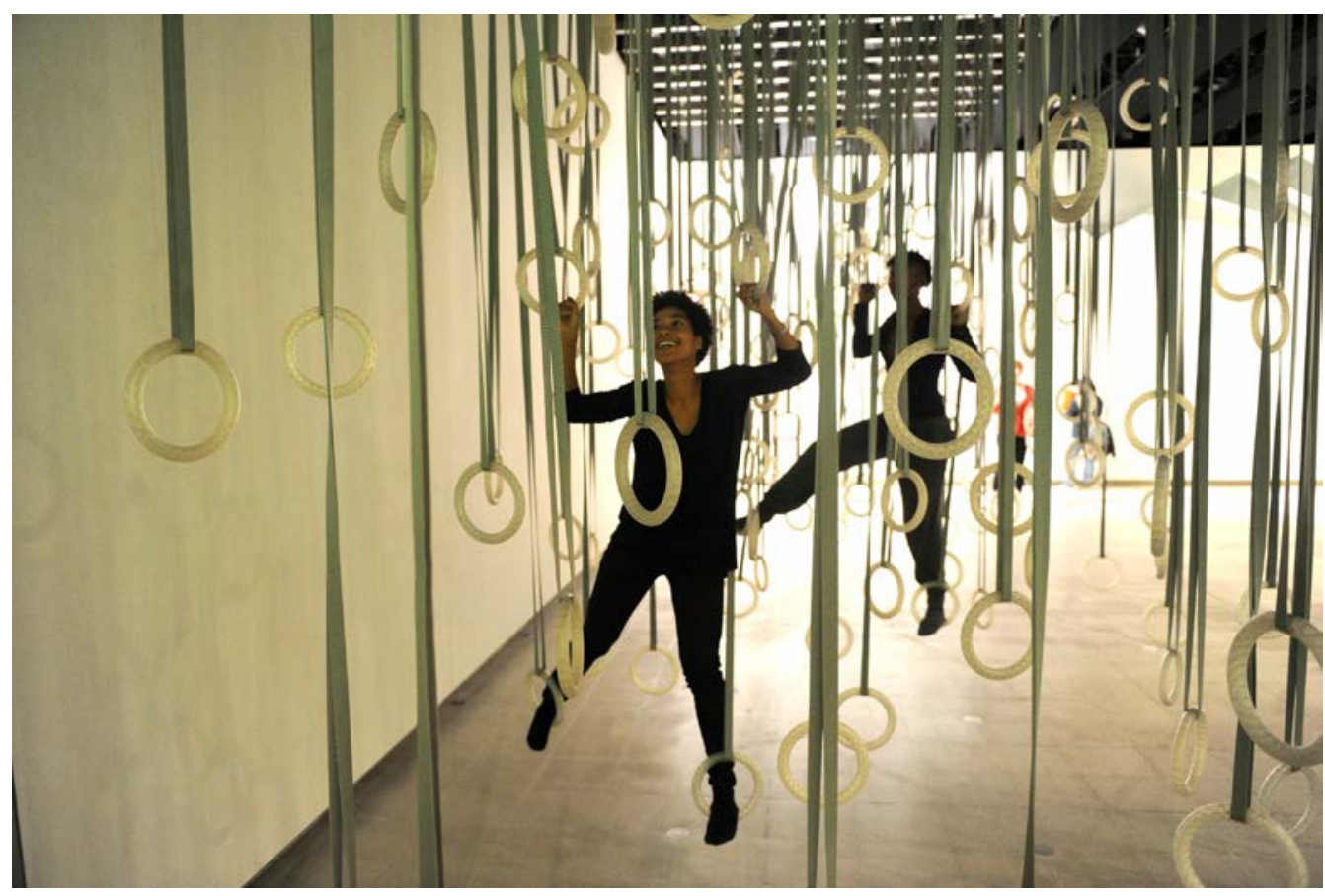

Figure 3. Visitors playing in William Forsythe's choreographic object The Fact of Matter, installation at Move: Choreographing You, Hayward Gallery, Southbank Centre, London, 2010 -2011. Photo: AlastairMuir/Courtesy of Hayward Gallery. 
In Forsythe's The Fact of Matter, which I experienced in the exhibition Move: Choreographing You at London's Hayward Gallery, the “object” is a participatory installation that invites visitors to climb through a very large number of rings hanging from straps at different heights - an obstacle course that seems enjoyably playful but turns out to be exceedingly tough. Almost no one is able to reach the other side without touching the ground or becoming too exhausted to continue. When I tried it I struggled for a long time, testing my strength and coordination while my body was constantly destabilized by the swinging rings. I had to give up when it became impossible to sustain. The sense of gymnastic play was supplanted by an emotional affect of disappointment, or rather a realization about the limits of my physical sense of capacity, the capabilities of my body.

This choreographic object could be considered an initially indiscernible instrument, and also a technical object in Gilbert Simondon's sense of a machinic system which requires techniques of adaptation or produces them, inducing a rhythm that moves with the machinic system's own force of organization. The machinic instrument is an ecology of associated milieus that in-form the body or the participant perceptual emergences (Simondon 2012, 51). Bodies inside The Fact of Matter are altered or affected in a way that they are also opened environmentally - or atmospherically - to the tentacular: transduced to objectness, gravitational pulls, sweat and quicker breathing, heat and melting down, in the billowing and swinging of the furnishings, with colors, contours and sounds of others, contours, room of blurred permeabilities. The forest of swaying rings prevails.

Now is a good time to mention common and uncommon senses in wearable space insofar as I want to draw attention to the phenomenological, sensorial-embodied perception approaches that underlie my writing here and point to the wearabilty of augmented virtuality design. VR worlds, I argue, can be like Forsythe's choreographic objects, entangling the subject while themselves being meshed and knotted of complex computational physics, graphics vectors and algorithms, the fact of virtual matter thus also becoming the subject wearing you and making you associate various uncouplings and reaccommodations. A virtual tamarind forest can play tricks on our minds, becoming an abstraction intensely impacting an unanchored body. I propose to look at different thresholds of perception - here in the context of 
dance and VR performance installations - which take us across not only various materialities but also divergent modes of physical thinking, to use a choreographic expression. Such thinking strays across sensing - listening, touching, smelling, swaying, reaching, flailing, disaligning, blurring - not necessarily based on visuality. It includes subliminal and peripheral sensing, rhythms of sensation, vibrations, proprioceptive and imaginary relations, dreaming, and dancing as a kind of morphing, detailing the imperceptible. The un-common senses, neuroscience philosopher Barry Smith proposed on a BBC Radio 4 program ${ }^{6}$, are the ones we are less conscious or clear about - thermo or mechanoreceptor nerves in fingers, arms, or the spine, giving us tingling sensations; skin and hair sensing temperature and wetness or feeling textures, though not reliably; muscles and ligaments that "hear” how our anatomies, the bones, minerals and water in bodies, move along and stumble about; how organism and metabolism are comfortable or tensed, affected and afflicted by the environment as well as internal biophysical processes.

An example jumps to mind, an idiosyncratic work by composer Yiran Zhao, titled SSH - Solo for Head, a one-on-one performance during which she asks the listener to close their eyes and wear ear plugs, while she touches their head and gently strokes their scalp, neck or ear lobes, gently rubbing fingers on hair and temples, fingering their echoing brain as it responds to physical impulses. The instruments, in this case, are the audience member's hair, ears, bones and the skin on the face (or of the beard). This reminds me also of Zhao's collaborator Kirstine Lindemann, a musician who taught me to listen to binaural audio recordings of ASMR (Autonomous sensory meridian response) - whispering performances that tend to generate an experience characterized by a static-like or tingling sensation on the skin, typically beginning on the scalp and moving down the back of the neck and upper spine. It has been compared with auditory-tactile synaesthesia.

If we leave vision aside and think of the digital context of art and all other popular cultural media of spectacular consumption (including games, of course, the primary landscapes of virtual reality environments), then we have to invoke numbers counting, measuring, moving forward, progressing, recounting, retracting - and thus the computational or algorithmic. The larger abstractions of our environment, our digital ground (cf. McCullough 2004), are now already being referred to as "the post- 
digital,” which can only mean that the digital has become commonplace and naturalized, no longer particularly noticeable - ubiquitous weather.

The be-holding of the not noticeable is a dynamic I want to reconnect to the hallucinatory, heightened sensuous pleasure of immersive aesthetics, as its inspiration has to do with the trans-sensory fluidity I wish to describe. ${ }^{7}$ The digital ground even of atmospheric, ambient interactivity is still a ground to walk on, hold on to when developing control over newly emerging corporeal rhythms (in associated milieus). Or are the refrains of moving or orienting altered when inside a virtual environment, when knowing one's body is affected by shifting from outside to inside a forest generated by VR technologies? Do we move from Schlemmer's phenomenologically centered Euclidian geometries of the human figure to a meta-kinespheric realm hat Laban had not imagined either? In Motion and Representation, Nicolás Salazar Sutil speaks of the "ecstatic position of digital technology," as if it were out of-body, luring us, so to speak, to forget ourselves and the ground we walk on, to "move beyond a present state of kinetic being...moving in 'ex-stasis'” breaking with our established kinetic spheres $(2015,75)$. These kinespheres (Salazar borrowing the concept from Laban) are topological movement ideas - physical movement understood in relation to basic properties of expenditure and recovery, like the breath that animates us.

Laban’s kinespheric architecture (for harmonious tracks of motion: high-low, forward-backward, right-left) does not necessarily determine movement but it seems to declare the orientations and directions which can then facilitate movement possibilities. When I look up into the air, or listen to sound waves, the bird song and crickets of my home valley, I also improvise. The scales and intensities may be different: I sense vibrations of after-images, dreams, memories - expanded sensorium of the hyperreal and of imagined exuberances. Immersion, therefore, takes on significance as a category of affective experience, as the term is now often used in conjunction with Virtual Reality, games and engineered atmospheres that range from the architectural, built environment, the urban spectacles of light and consumerism, to the various intimate aesthetic experiences designed by performance and sound makers, fashion and interaction designers, or biotechnological and bioscientific experimenters. Prostheses create affordances that point to their Umwelt, enabling new qualities of existence, relationships, inhabitations. My own sense of immersion as a 
technique, however, is derived from dance. VR designers, such as Jaron Lanier, may also dance as/with their avatars, but their initial questions are different, for example pointing to mapping, i.e. controlling motion in virtual environments, making measurements on the body of someone wearing a capture suit, calculating an aspect of the flex of a wrist, to be applied to control a corresponding change in a virtual body. Immersive virtual reality allows persons to inhabit avatar bodies that differ from their own; this can produce significant psychological and physiological effects, of course, and Lanier's concept of homuncular flexibility (Lanier 2006) proposes that users can learn to control bodies that are different from their own by changing the relationship between tracked and rendered motion. In later research at Stanford, Lanier and his team examined the effects of remapping movements in the real world onto an avatar that moves in novel or unusual ways (Won, Bailenson, Lee, Lanier 2015) - thus shifting the mapping of one's physical anatomy (in the motor cortex) to rather different homuncular and eccentric "body schemas," avatar creatures that are indeed virtually different (Lanier mentions a lobster with a trio of little midriff arms on each side of its body).

\section{Homuncular Environments}

The virtual differences that interested me were atmospheric, not avataric, and thus I turned to habitats of certain colors, textures (red sand) and tropical vegetation, with dynamic elements that incite immersants to bathe in them, to dive, surf and fly across the currents of such kimospheres: to imagine becoming bird-like. The aesthetic theories of atmosphere (cf. Böhme 1995; Zumthor 2006; Pallasmaa 2014), derived from philosophy and cultural geography, now also relate to stage design, architecture as stage design, to questions of how designed space surrounding our bodies affects our emotions and moods. When speaking of augmented reality in theatre or music concerts, we imply that the physically affective is amplified through technical means (sound diffusion, digital projections, lighting, etc), and thus an expanded sense of the choreographic as wearable space is evoked, with alchemical dimensions and corporeal-perceptual irruptions. Augmented space enters us and our receptors receive many (often ambiguous) clues. 


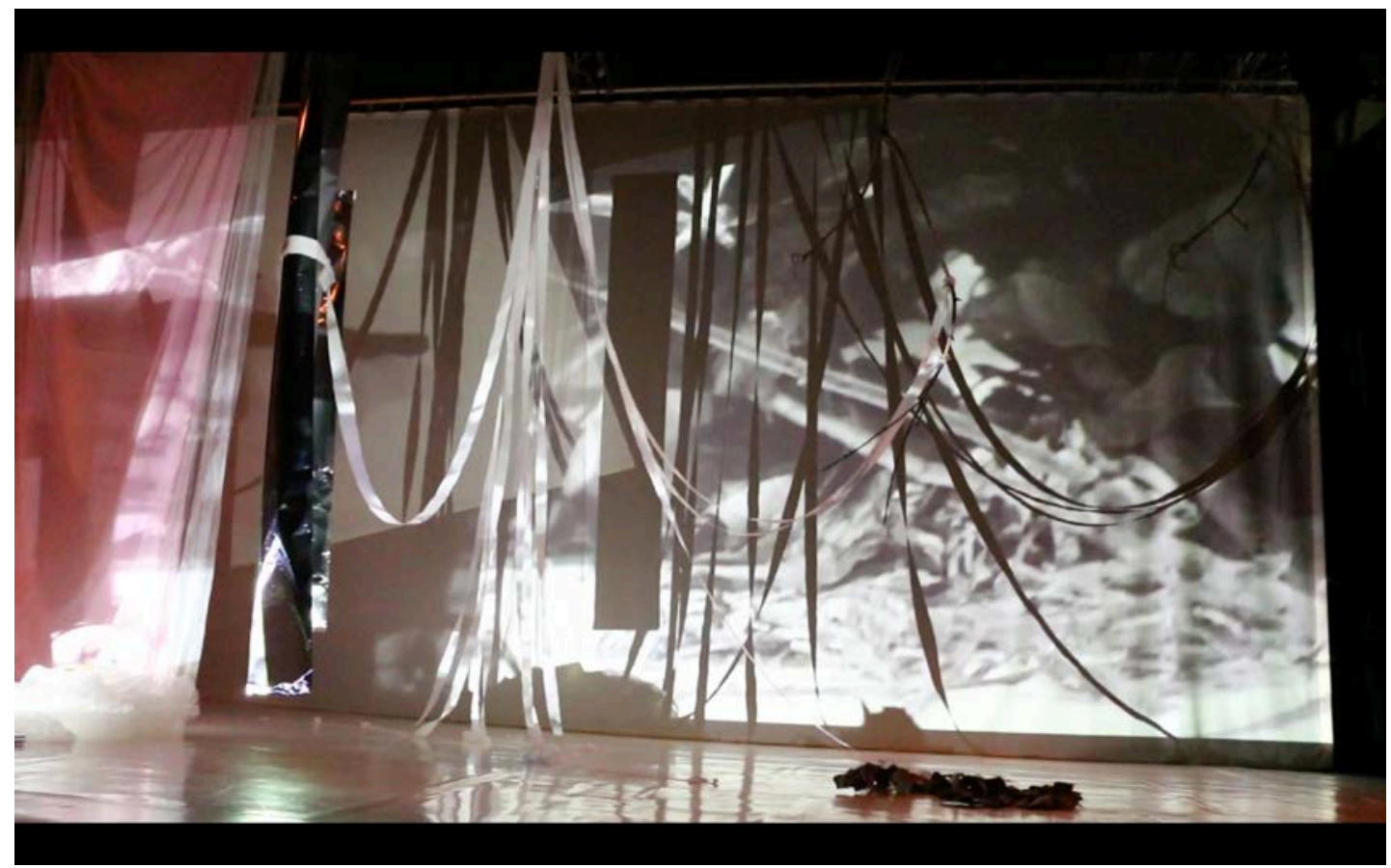

Figure 4. Augmented reality/digital forest. “Constructing Realities” workshop. CNDP Bucharest, 2018 (c) DAP-Lab

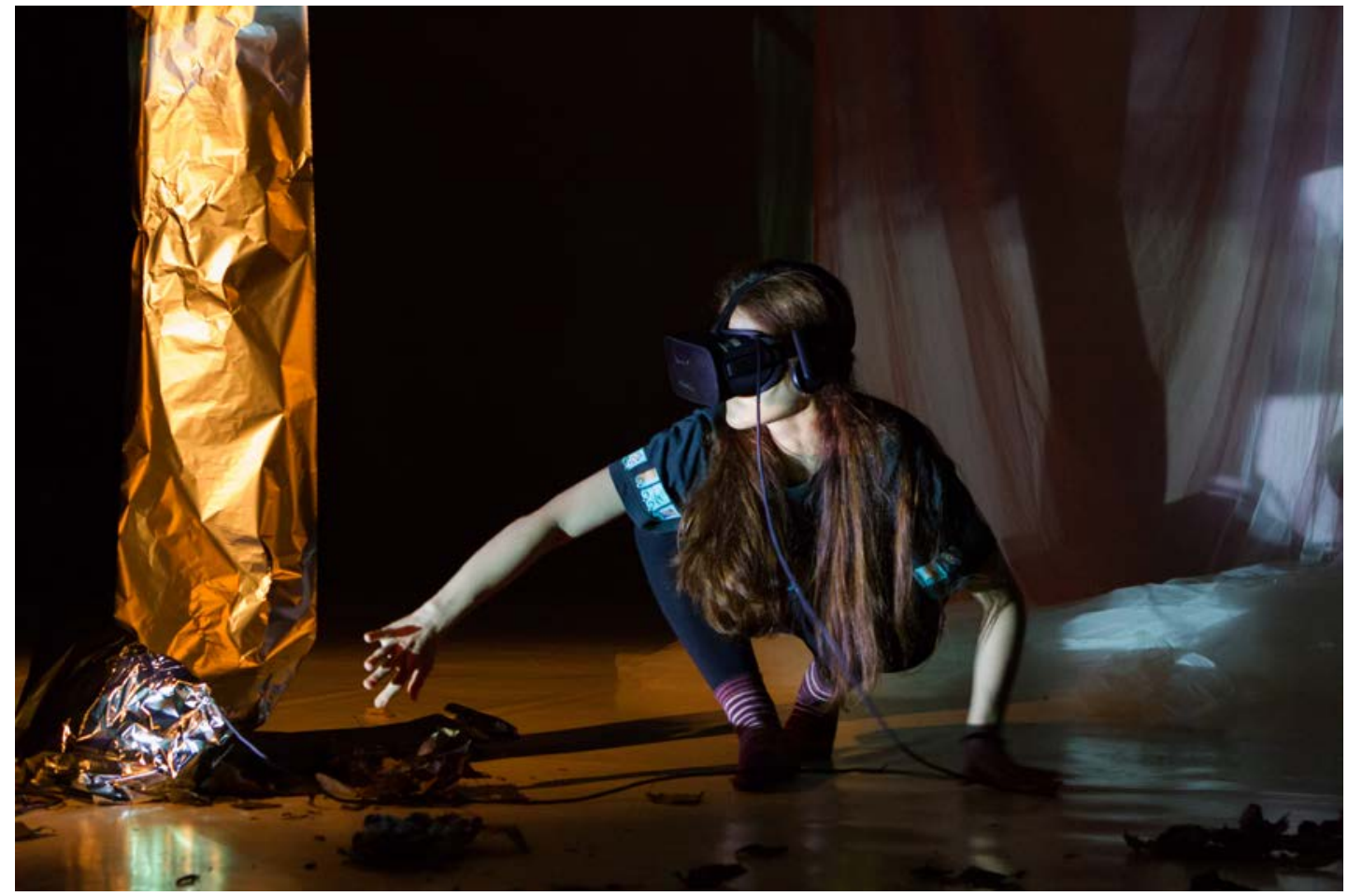

Figure 5. Visitor touching branch in virtual forest, inside augmented virtuality space where the sound of the suspended silver foil creates a rustling (of leaves). CNDP Bucharest, 2018 ㄷ DAP-Lab

The fullness of the real returns in such densely sensorial atmospheres of performance rituals we long to rediscover - immersion is craved, the sublime, the erotic and rapturous desired. ${ }^{8}$ The craving seduces the wearer of goggles to worry less about the 
visual VR experience but to "touch" space and transfer to other perceptual realms, perhaps even enjoying the sense of uncertainty in the restricted virtual space (green grid lines popping up if the wearer walks too far). Exploring such imaginary limits and contagious material conditions, our DAP ensemble tries to fabricate hallucinations, using very simple effects of augmented virtuality.

In a recent rehearsal, after having suspended large amounts of delicate, sensual white fabric from the ceiling of a warehouse, attached to aerial wires that allow the gauze to fly, I watched how dancer Yoko Ishiguro - eyes closed - slowly emerged, like an amphibian creature, from under the fabrics, still shrouded by them, then extending the large dress so that it stretched out almost the whole length of the building. As we walked around, trying to disentangle with eyes, ears and sensory touch what was unfolding, a tiny whirring sound was heard coming from the cone-shaped origami object she held in her hand: a sound instrument, reflecting dimly the blue light that shone on it. She used it as a kind of echolocation device. We call it "Kepler" - named after the recently discovered 452b exoplanet and constructed by my design collaborator Danjoux out of the same polypropylene material as the costume for one of the dancers. The costume, in turn, was inspired by an interactive architectural origami structure we had been asked to perform with by the Hyperbody architects from TU Delft (Birringer 2017, 36-41).

Materials, in other words, transitioned and became transformed, from architectural animation to wearable, from sounding/conductive costume to sound-objectchoreography - re-contextualized kinetic characters, masks and accessories, eventually also built into a simulated tamarind forest. The sensory atmosphere thus impregnates aural and tactile experience while it implies movement, a "trans" motion across. Performing (with) architecture, then, is one of the sensory challenges I propose here for embodied scenography. But it is a (twenty-first century) step further ahead from the Bauhaus. How does embodied scenography enjoin with spatialities both material and virtual? A haptic feedback relation seems inevitable, when we speak of feltness of these different materialities.

In kimosphere no. 4 (2017), first staged at the Artaud Performance Center in London, we tried to test the haptic feedback by physically sensualizing the performers' 
imaginative processes. We wanted them to become tangibly engaged in the virtual with their common and uncommon senses, touching things that were not there. Thus, with our dancers a part of the kimosphere, sometimes acting as guides, the audiences become the performers invited to step inside the physical landscape and touch, listen, move around and at some point put on the HMD to enter into the virtual environment. With the goggles, the wearer dives into abstractions, i.e. a tropical rainforest that is clearly digitally fabricated and not real. They cannot see their own extensions (say, their hands or feet) in the layered environment, but they can feel them or compensate (when they touch a branch, the sand, or leaves on the floor) by trying to balance their bodies "floating" in destabilized architectures. They reach, as they feel urged to touch the tamarind trees or the grass. Some of the visitors, perhaps unaccustomed to VR, choose to sit or lie down, yet move their bodies around, turn, twist. They appear to hover in the tropical surreal, and at the same time are surprised by events they may not suspect (wind touching cheeks, smell of moss and tree bark, crackling sound of branches, etc).

Hovering presences - where atmosphere also appears uncontrollable, emergent evoke complex ontological and spiritual questions. The wildness of nature - I remember growing up as a child of dark forests and steep hills - is perhaps harbored deep inside our skin and bones, our muscle memory, internal perception and emotional conditioning. The wildness may also be imaginary - the forests, hills, and the fog a scenography of ghost stories, myths, fairy-tales with which I also grew up and which is refreshed when I am exposed to the smell of moss, the touch of mist on my skin, or the aura of diffused light when sun beams flicker through tree branches, and hundreds of flies somersault. How are we to think, then, of trans-sensory hallucination as other than an effect of elemental materiality in contagious synaesthetic constellations? The forest touches us.

The production of atmospheric conditioning through design, with sensorial impact on perception and also ethical perspective (namely how to react to affective presences and interact with lurking environments), thus points to material assemblages. Augmented virtuality, where a real branch reaches into an unreal simulated tamarind forest, transforms the destabilized, solitary proprioception into more collective "seeing” that no longer arises just from eyes (looking at the VR world through 
goggles without peripheral vision of one's own body and limbs) but slides into audible-visceral environments. The homuncular innervation and the "seeing" with phantom limbs are felt sharingly: audiences inside VR also touch and are touched by dancers outside of VR. The cortical plasticity implied by such innervation and alteration (first a dry branch, then wet algae are grasped) allows the wearer perceptual rearrangements. Sensory feedback of new affordances overtakes them, perhaps in a manner of shamanic rituals where spirits descend to heal with their powers. They make us dwell in a shared circle of continuous community. Visitors are aware of the co-presence of others wandering around the milieus, before each of them mounting one of the HMDs to slip away into the forest.

\section{Virtual Handovers}

Possession rituals involve trances that are often induced by music, drumming, chanting and dance. We recall Maya Deren's powerful films she recorded in Haiti (Ritual in Transfigured Time, 1946; Divine Horsemen: The Living Gods of Haiti, 1977). ${ }^{9}$ In her writings Deren describes the intercourse with Vodou possession ceremonies as transformational rituals, allowing a de-centering of self, ego and personality. Such de-centering I associate with Fayen d'Evie's suggestions about blundering and be-holding, when she notes that her installations for vision-impaired audiences shift sensory attentiveness to tactile movement perceptions, encouraging “vibrational strategies” (d'Evie 2017, 48) for audiences that “lean” into the work differently through tactile, kinaesthetic entanglement. This leaning could also be considered central for wearable space in exhibitions with VR landscapes.

D’Evie speaks of stories “told through blindness, with a vibrational narrative that will blunder amongst macro propositions, with intermittent be-holding of sensory recollections" (2017, 42). Her notion of be-holding is fascinating as she explains the grappling with fugitive, hallucinatory, and tenuous “threads” in an aural environment, or an environment of sculptural objects that are touched and grasped, through the word's etymological root (before the ocular), namely holding, handling, guarding and preserving. Such handling, in the curatorial practice d'Evie describes, means haptic engagement and intercourse in the way in which she admits learning from 
choreographic practices, in particular Forsythe's choreographic objects, which she analyzes and then proposes to reorient through blindness (2017, 50-54). In Tactile Dialogues (2016), a work she developed in Moscow with choreographer Shelley

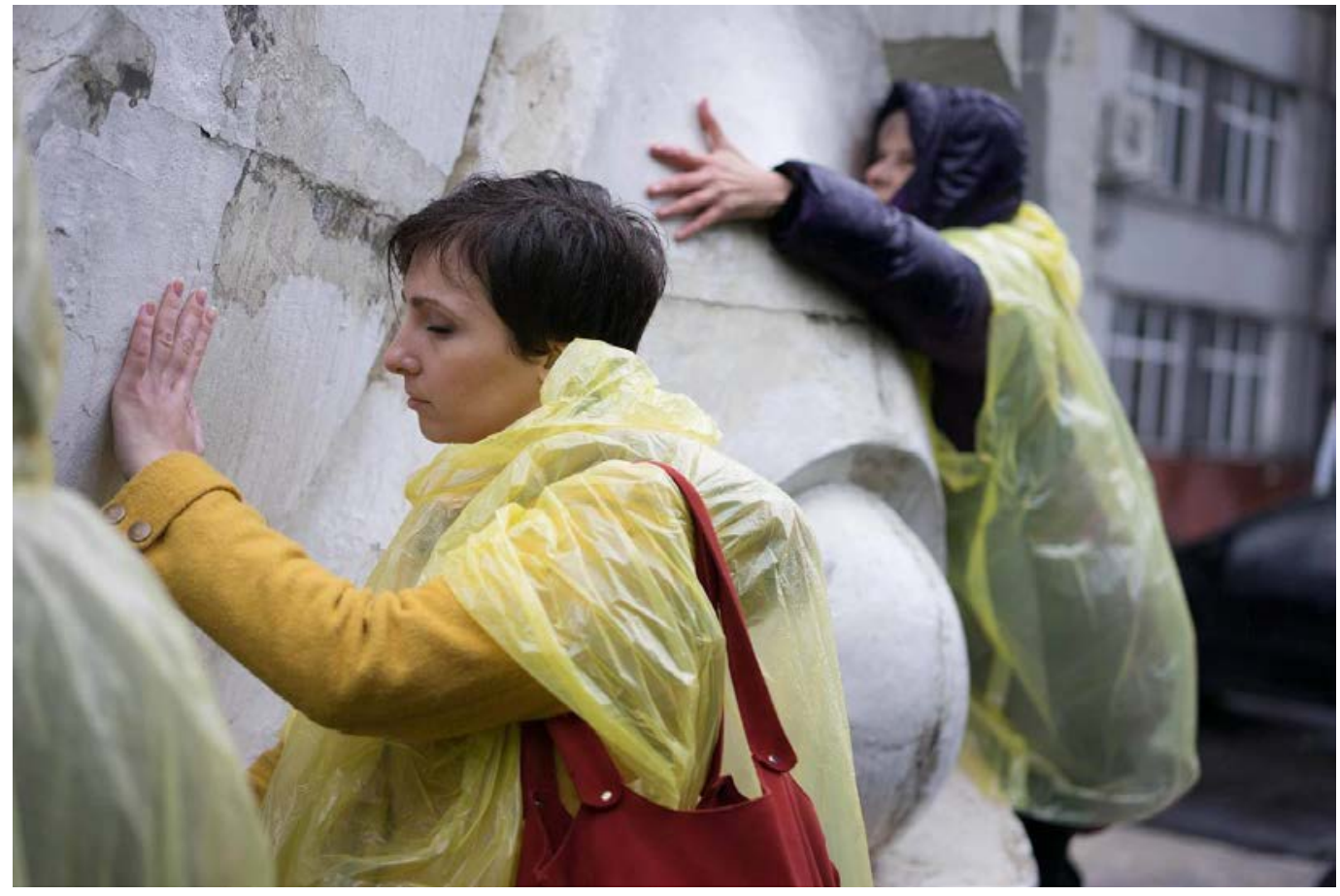

Figure 6. Tactile Dialogues (Vadim Sidur), curated by Fayen d'Evie and Shelley Lasica with Irina Povolotskaya, 2016. Photo: Evgeniya Chapaykina

Lasica, she invited participants to share actions handling objects or architectural structures, giving attention to temperatures, textures and tactile surfaces and also of course the kinaesthetic angles of encounters or navigations around such materials. The instigations addressed in d'Evie's provocative work with "handovers” and intersensory translations point to an important new understanding of kinetic atmospheres. What she calls "epistemology of hallucination” $(2017,58)$ is their unfolding through affective connections that may not depend on, or exceed, conscious apprehension. The repertoires in dance which I have become interested in over the past years (body-weather inspired) have helped me to become more attuned to complex transitions between ephemeral performance, mediation, and design.

\section{Changing Repertoires/Hallucinatory Scenographies}

In conclusion, I evoke the kimospheres created by DAP-Lab in recent years. Whereas 


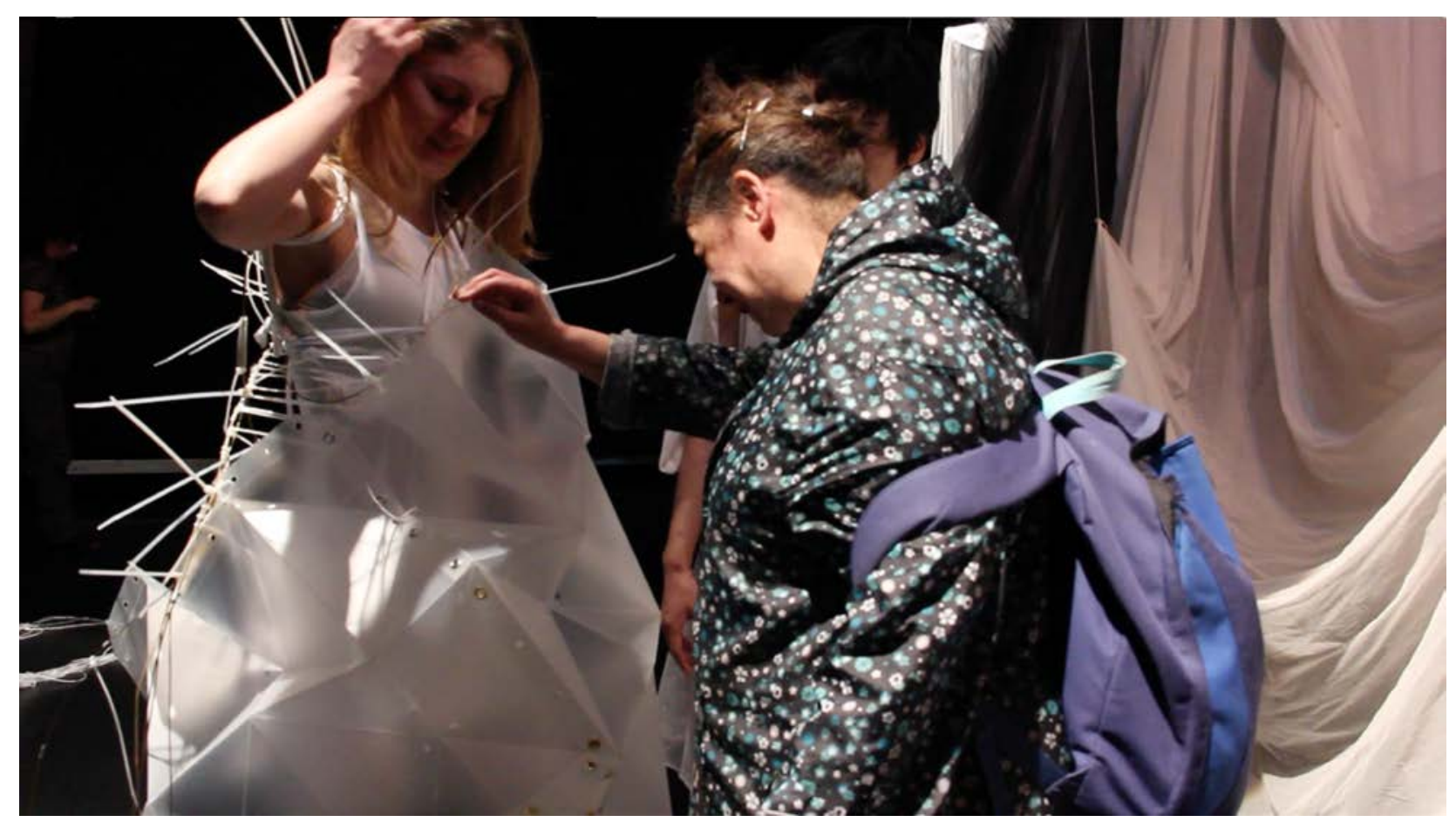

Figure 7. Vision-impaired audience member touches dancer's costume in metakimosphere no.3, OrigamiDress design by Michèle Danjoux, 2016 C DAP-Lab

kimosphere no. 3 addressed vision-impaired audiences specifically through touch, asking visitors to imagine what they felt and heard (OrigamiDress eliciting its own sound with the crackling pops of the folded polypropylene), the next installment, kimosphere no. 4, was open to a general audience offering stations in a large theatrical architecture where real and virtual forests merge, handed over to each other with the virtual complementing the real in a tangible way - realities layered on top of and within each other. This augmented virtuality is introduced by a poetry game, "Red Ghosts," playable at a console by each visitor so inclined, their feet stepping on real leaves and twigs. The layering invites different experiences for each audience member, creating a sense of their own emerging views as they construct a narrative that flows through the collective body of the audience. "Red Ghosts" is also intoned: a recorded voice speaks about lemurs - the moonlit acrobats of Shadows in the Dawn (a field report by primatologist Alison Jolly in Madagascar) - evoking an allegory of evolutionary migration over millions of years when the red island drifted off the East African continent (Lasky 1998).

The lemurs are the ancestors in this scenographic landscape. The slow time/slow space was pertinent for the temporally extenuated experience we had devised for the theatrical environment of kimosphere no. 4. The atmosphere and the audience are the 
scenographic weather - the audience produces a sense of immersion for themselves, tuning into (or out of) a forest of sensorial stimuli they instantiate into their immersive experience. They explore forest knowledge, and the landscape is the protagonist.

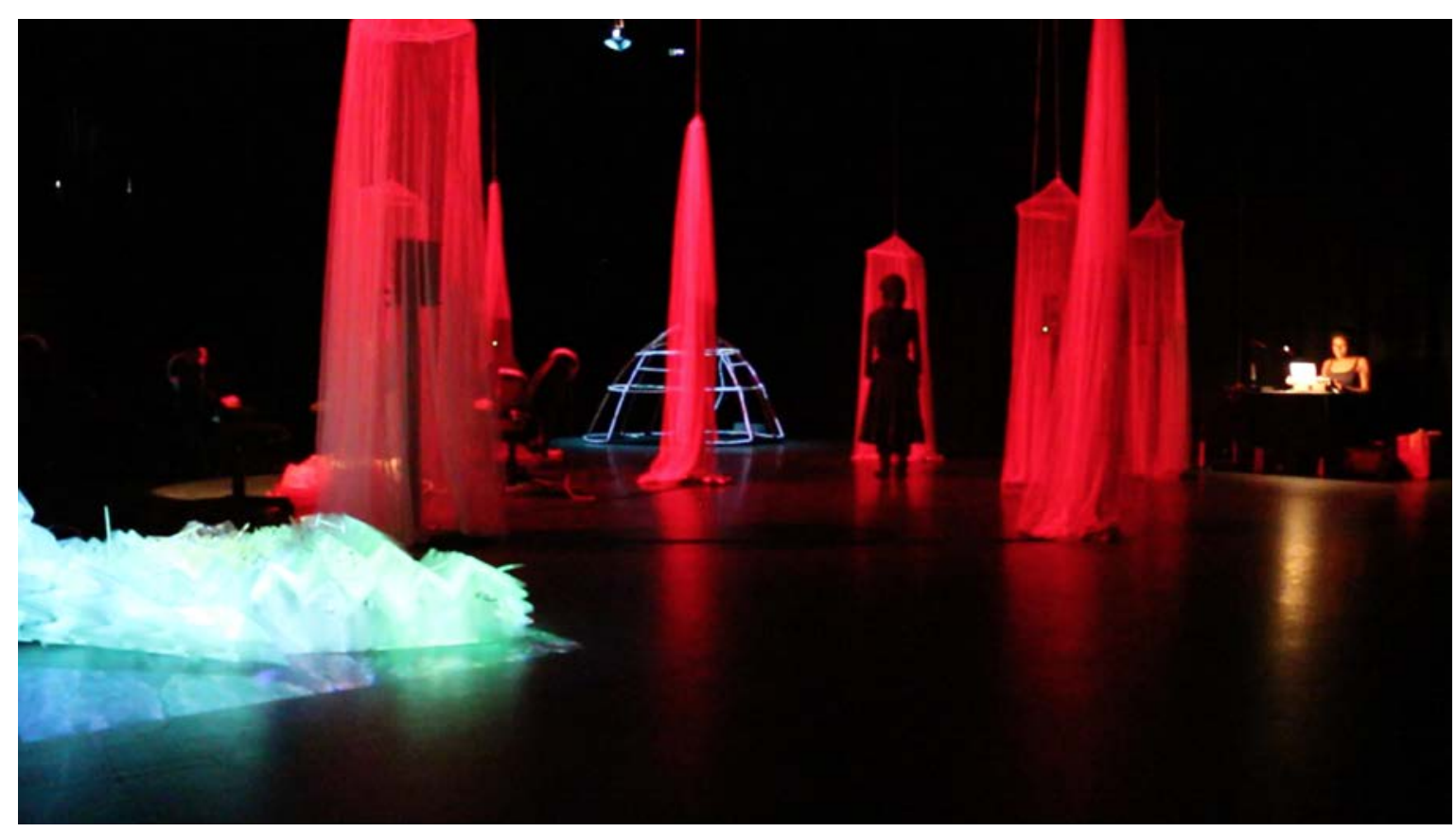

Figure 8. kimosphere no.4: dancer Yoko Ishiguro, standing still inside one of the 8 ghost speakers; the coral reef is on the left, and sound artist Sara S. Belle performs in the background right. The skeleton of the Soundsphere is visible in the far back. London 2017 (C) DAP-Lab

Sound and tactile materials move this kinetic poetry, disseminate it around the architecture of the whole, with voices, electronic sounds, echoes, processed natural sounds, distorted crackles and hisses, light, colors and moving textures. The 8-channel installation, with each speaker shrouded in a mosquito net suspended from the ceiling grid, maps a kind a metaphorical forest of ghostly presences in deep red light (three dancers, wearing masks, are hidden inside, still or barely moving). Dense layers of sound-in-motion is experienced by visitors while wandering around the forest of speakers - the micropolyphanies in fact only audible if they do move between the nets, listening and absorbing. There are stations on the perimeter: a VR-headset and five lighter "google cardboard" 3D headsets (with inserted iPhone); an igloo-like Soundsphere where visitors crawl inside to explore a GSR biosignal interface (listening to galvanic skin response turned into sound); and a coral reef sculpture where they can lie down and float inside a deep sea digital projection that percolates over a synthetic origami architecture. 


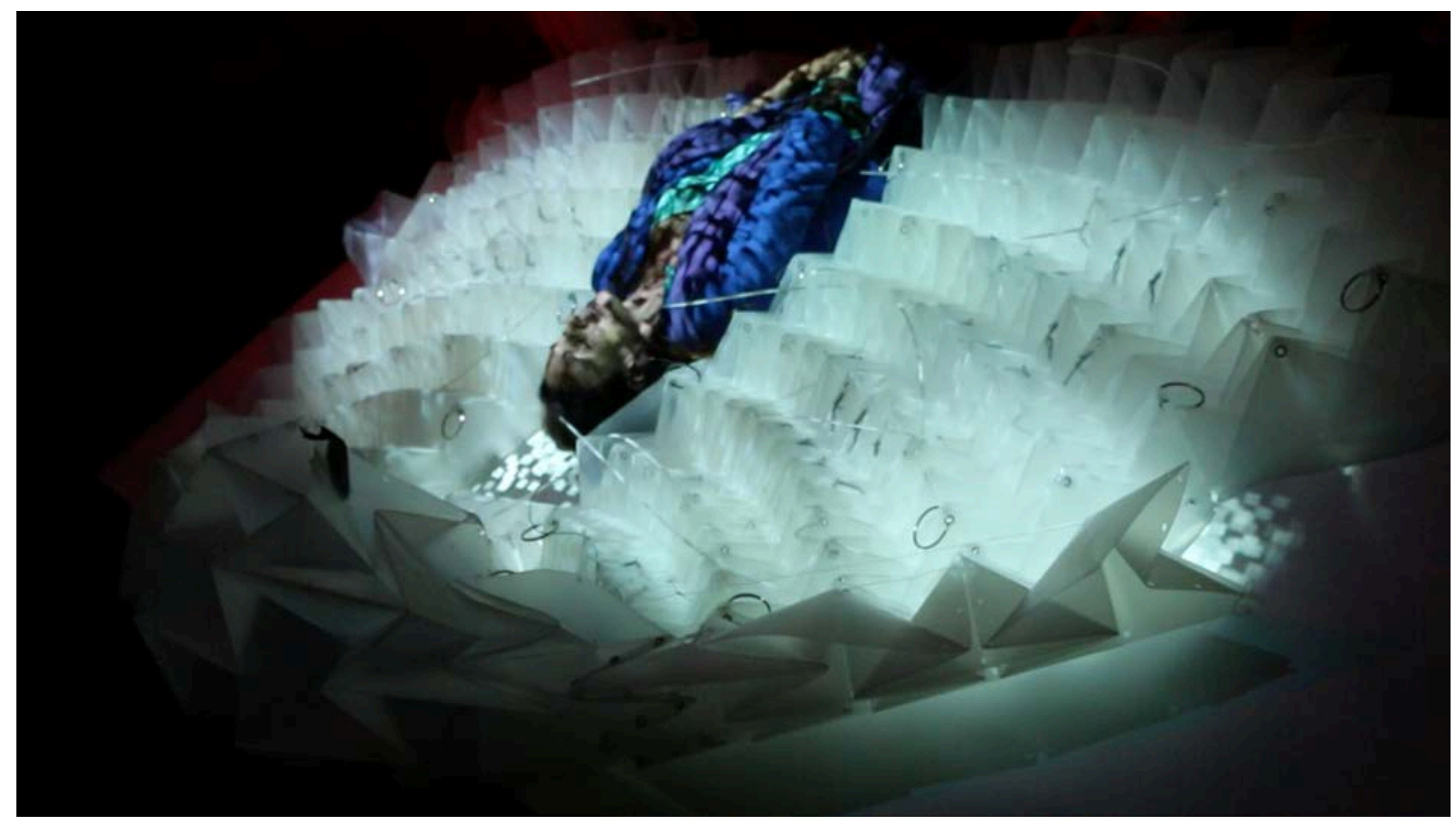

Figure 9. Visitor having dived into coral reef and watery projection, kimosphere no.4 @ DAP-Lab

The ritual-communal aspect of immersion is an important concern, otherwise there would be no reason to experiment with these forms of interaction. Kimospheres suggest a scenographic strategy engaging audiences to step inside and come closer, touch, listen and act in greater intimacy with unfolding actions. They are breathing spaces, currents felt through sonorous, tactile connections. Surfaces and the blurring of the physical-virtual boundary require a creative investment from the audience, particularly in the case of the VR masks that need to be worn.

It is not a big shift from digital projections (as part of the installation architecture and its lighting) to other-worldly immersion. 3D film or VR is still a cinematic projection medium, but it has enhanced its plasticity and the illusion of absorption (of the viewer feeling being inside rather than looking from the outside in). 3D interaction designers argue that such absorption - and what our collaborator Doros Polydorou refers to as the perception of being physically present in a non-physical world - relies on the plausibility illusion, namely that you are not only feeling your body to perceive in the way you normally do, but that the environment believably responds to your actions to make you think it is real and navigable. DAP-Lab’s research on formative and wearable space $^{10}$, on mediated and yet highly visceral environments, provides the basis on which to propose a new immersion-dance, with “full-body masks,” also 
questioning these notions of plausibility (since they are ocularcentric). Kinetic immersion includes motion of light, pixels and graphic projection, diffusion of sound waves, energy fields, color fields, implausible edgespaces and anomalies, fantastical creatures and the homuncular that can be touched, handled, prodded and dragged, thus many different forms of embedded motion sensing which result in environmental reactions.

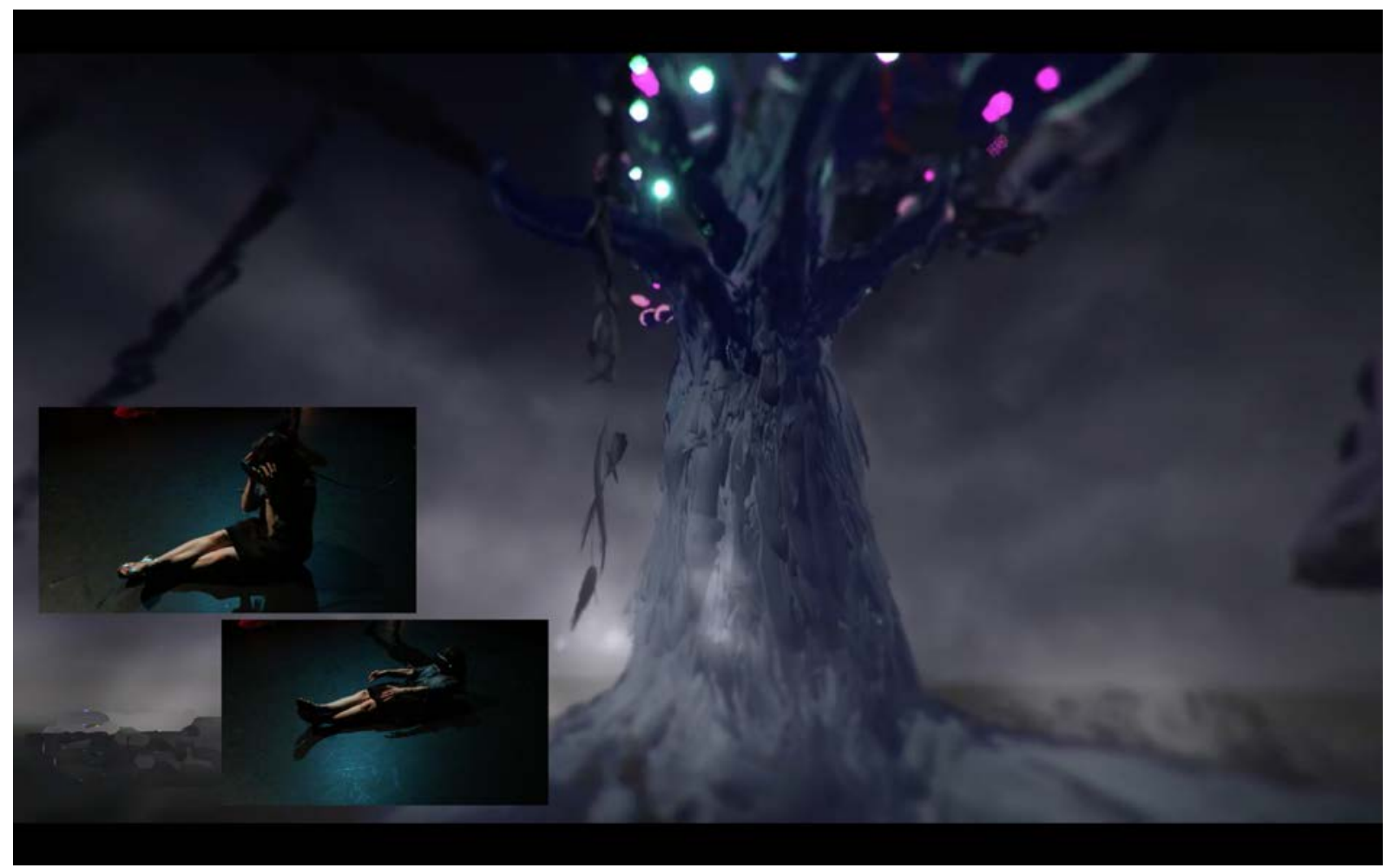

Figure10. Visitor enacting/embodying what she perceives inside "Lemurs" forest interface with VIVE goggles, conducted by Doros Polydorou, kimosphere no. 4. 2017 (C) DAP-Lab

This extended choreographic materially reproduces itself even when there is only breath (internal movement) which is of course also touch. Breath not only moves space - inhaling/exhaling, expanding/contracting - but also is audible. In all kimosphere installations the biophysical, etheric sound is amplified. The elemental thereness of the animic atmosphere includes the audience as experiencers who are "inside" the atmosphere, and the atmosphere is in them. The extended choreographic includes intimate personal, meditative resonances derived from the floating "coral reef" or the "Red Ghost" poetry game, and collective encounters with others in the red forest; then there are the VR interfaces where visitors enter ghostly worlds via goggles. Kimosphere no. 4 thus combines real/virtual atmospheres both actuated 
through the same tactile narrative, neither quite plausible and yet transforming ways of knowing the body and how it acts in gravity-bound space. We cannot predict how visitors project the evolutionary tale of the lemurs migrating from Africa to Madagascar. Yet the critical aspect for us is the immersants' sensory participation, letting resonances of real and virtual spaces become rhythmically entwined.

The occurrent gestures become reciprocal: pushing the kinaesthetic into a perceptual virtuality (VR) that as yet is largely constrained in the visual (the ergonomic challenges with VR headsets are known; these masks are tethered with thick cables to computers, thus a visitor putting them on has to be helped by a conductor). But the gestures' homuncular flexibity feeds virtual playful affordances back to the corporeal, pouring them back into the player's trance-actions (Fig.12). The kinematic is the challenge for a VR scenography which does not insulate/isolate the immersant or focus on visuality but allows for an expanded synaesthetic entanglement where imagined physical virtuality feeds back into the body schema. The momentary insulation from other visitors/friends, during kimosphere no. 4, turned out not to be a problem: everyone seemed patient, waited for their turn, observed, chatted and commented upon one another's be-holding and handovers, the choreographies of walking into the lemurs' forest, flying up trying to catch a glimpse of the moonlit acrobats.

\section{Notes}

I wish to thank Michèle Danjoux, designer and co-director of DAP-Lab, and all ensemble members and collaborators in the kimosphere series for their vital artistic co-operation. I also thank Doros Polydorou for designing our VR landscapes and introducing me to "homuncular flexibility."

${ }^{1}$ For a cautionary and critical introduction to the "moving objects" (the works, pedagogies, legacies) of the "disappearing Bauhaus", see Saletnik and Schuldenfrei (2009, 1-9).

2 The Design and Performance Lab (DAP) was founded in 2004, and has produced a number of telematic/networked and onstage performances, most notably Suna no Onna (2008), UKIYO (2010), and for the time being (2012-14), the latter a suprematist homage to the early futurist opera Victory over the Sun created by Kruchonyk, Matyushin, and Khlebnikov, with designs by Malevich. Since 2014, DAP-Lab cooperated on the European METABODY project (www.metabody.eu), 
with other arts organizations and research labs including Reverso, Hyperbody, STEIM, InfoMus Lab, Stocos, Palindrome, K-Danse, and Trans-Media-Akademie Hellerau (Birringer 2017). After of a joint production in Madrid with the Hyperbody architects from TU Delft, DAP-Lab staged a series of six kinetic atmospheres between 2015 and 2018, in Madrid, Paris, London, and Durban, South Africa. The next installment premieres at ISEA 2019 in Gwangju, S. Korea. Filmic excerpts of many of these works are available online; DAP-Lab's website is here: http://www.brunel.ac.uk/dap. On the website are numerous links to publications, conferences and exhibitions that featured our innovations in wearable design, created by fashion designer and co-director Michèle Danjoux (http://www.danssansjoux.org). ${ }^{3}$ Some researchers prefer the term VE (virtual environment) to draw attention to a body's remaining environmental/spatial connection, even if the VR headset or headmounted display (HDM) is restrictive like a blindfold and blocks out all visual information from the surroundings. The VIVE and Oculus Rift headsets are the most commonly used ones. Sensory navigation and orientation continue in the virtual world that is layered over the concrete one. Cf. Thomas and Glowacki 2018. The goggle systems so far were mostly cable-connected to the computer hardware; the new VR generation, with Oculus Rift, will use wireless system so that movement will become less restricted. The term augmented reality (AR) refers to interactive experiences of a real-world environment where the objects that reside in the real-world are augmented by computer-generated perceptual information. When we began to use VR headsets in our installations, we tried to invert the ocular-centric headset information with supplementary real world organic objects and tactile occurrences (air/wind, smell, temperature, pressure, contact, etc), thus the somewhat paradoxical or ironic term augmented virtuality, which probably was known in the interaction design, human factors engineering and 3D visualization communitiers for some time; see Milgram and Kishino 1994.

${ }^{4}$ I describe an extensive outdoors "blind-folded” exercise I did with eyes closed during the workshop E/motion frequency deceleration Choreolab in Krems, Austria (Birringer 2016). In the same laboratory we also practiced butoh and body weather techniques (the latter derived from the field teachings of Min Tanaka). For my forays into choreographing moveable space (interlinked with telematic space), see Birringer 2010. My work with networked performance spaces dates back to the early 2000s when I co-founded the ADaPT collective while conducting digital and motion capture research at Ohio State University.

${ }^{5}$ It was fascinating to find out that Schlemmer, during the early 1922 Stuttgart performances of the Triadic Ballet, was one of the three performers wearing the constrictive costumes himself, discovering that unfortunately he "could not see the scenes in which he performed and hence did not have an overall picture of the performance" (Schlemmer cited in Cramer 2014: 22). He also comments on the differences in techniques, e.g. how trained dancers like Albert Burger and Elsa Hötzel might wear the elaborate full-body sculptures and oversized masks, compared to nontrained performers.

6 Barry Smith, with sound artist Nick Ryan, “The Uncommon Senses Radio Series," BBC Radio 4, March 2017 (www.bbc.co.uk/programmes/b08km812/episodes/player). ${ }^{7}$ My writing is derived from a recent talk I gave on the subject of sensorial techniques of public engagement (engaging audiences through immersive methods); reflecting mostly on my choreographies, public workshops and installations, I also drew inspiration from d’Evie 2017. 
${ }^{8}$ Examples from the recent history of music and sonic art are too numerous to cite, ranging from Xenakis, Paik, Lucier, and Stockhausen to drone and noise artists (Niblock, Fusinato, Ikeda) and sound installation artists such as Cardiff, Heimbacher, López, Wollscheid, Leitner, Suzuki, etc. On occasion, the reach for the sublime crumbles into the solemn pathos of the quasi-religious (e.g. Rirkrit Tiravanija's mise en scène for Stockhausen's Oktophonie, staged at New York's Park Avenue Armory in 2013).

${ }^{9}$ Haein Song, a dancer/choreographer who practices kut, the traditional Korean shamanic ritual performance, recently completed a series of works that intermesh the traditional and the digital. She describes the ritual techniques (mugu) deployed to achieve the desired collective healing and well-being effect of the practice in Ecstatic Space: NEO-KUT and Shamanic Technologies, $\mathrm{PhD}$ thesis, Brunel University London, 2018.

${ }^{10}$ Cf. Danjoux 2014, 2017 and Birringer 2010. For the kimosphere no. 3 staging, arranged for vision-impaired visitors from the Ealing Association of the Blind, see https://www.youtube.com/watch?v=5DdAcv37jmc. For kimosphere no. 4, see https://www.youtube.com/watch?v=0aIW6Klfm1g.

\section{References}

Bauhaus: Art as Life. An exhibition at the Barbican Art Gallery, London, May 3 August 12, 2012.

Birringer, Johannes. 2017. 'Metakimospheres.' In Susan Broadhurst and Sara Price (eds), Digital Bodies: Creativity and Technology in the Arts and Humanities. London: Palgrave Macmillan, pp. 27-48.

Birringer, Johannes. 2016. 'Really Actually Windy: On Environments, Technologies and Dividual Performances.' Theatre Journal, 68 (4): 633-647.

Birringer, Johannes. 2013. 'Bauhaus, Constructivism, Performance.' PAJ: A Journal of Performance and Art 104, 39-52.

Birringer, Johannes. 2010; 'Moveable Worlds/Digital Scenographies’. International Journal of Performance Arts and Digital Media 6 (1): 89-107.

Blume, Torsten. 2014. 'An Undertaking Contrary to Nature for Purposes of Order.' Bauhaus: Zeitschrift der Stiftung Bauhaus Dessau 6: 4-13.

Böhme, Gernot. 1995. Atmosphäre: Essays zur neuen Ästhetik. 7th edition, Frankfurt: Suhrkamp.

Böhme, Gernot. 2017. The Aesthetics of Atmospheres: Ambiences, Atmospheres and Sensory Experiences of Space. Trans. Jean-Paul Thibaud. London: Routledge.

Cramer, Franz Anton. 2014. 'In the Here and Now of Geometry.' Bauhaus: Zeitschrift der Stiftung Bauhaus Dessau, 6: 19-29.

Curtin, Adrian and Roesner, David. 2015. 'Sounding out 'the scenographic turn': eight position statements.' Theatre \& Performance Design 1 (1): 107-25 
Danjoux, Michèle. 2017. Design-in-Motion: Choreosonic Wearables in Performance, PhD Thesis, London College of Fashion, University of the Arts London.

Danjoux, Michèle. 2014. 'Choreography and Sounding Wearables.' Scene 2 (1-2): 197-220.

D’Evie, Fayen. 2017. 'Orienting through Blindness: Blundering, Be-Holding, and Wayfinding as Artistic and Curatorial Methods.' Performance Paradigm 13: 42-72.

Gaensheimer, Susanne and Kramer, Mario, eds. 2016. William Forsythe: The Fact of Matter. Bielefeld: Kerber Verlag.

Ingold, Tim. 2011. Being Alive: Essays on Movement, Knowledge and Description. London: Routledge.

Krauss, Rosalind [1978] 1986. 'Sculpture in the Expanded Field.' In The Originality of the Avant-Garde and Other Modernist Myths, Cambridge, MA: MIT Press, pp. 276-290.

Lanier, Jaron. 2006. Homuncular Flexibility. Seattle: Edge Foundation, Inc.

Lasky, Kathryn. 1998. Shadows in the Dawn: The Lemurs of Madagascar. San Diego: Gulliver Green.

McCullough, Malcolm. 2004. Digital Ground: Architecture, Pervasive Computing, and Environmental Knowing. Cambridge, MA: MIT Press.

Milgram, Paul and Kishino, Fumio. 1994. 'A Taxonomy of Mixed Reality Visual Displays', EICE Transactions on Information Systems, vol E77-D, no.12. Available online: http://etclab.mie.utoronto.ca/people/paul_dir/IEICE94/ieice.html

Pallasmaa, Juhani. 2014. 'Space, Place and Atmosphere: Peripheral Perception in Existential Experience.' In Christian Borch (ed) Architectural Atmospheres: On the Experience and Politics of Architecture. Basel: Birkhäuser Verlag, pp. 18-41.

Salazar Sutil, Nicolás. 2015. Motion and Representation: The Language of Human Movement. Cambridge, MA: MIT Press.

Saletnik, Jeffery and Schuldenfrei, Robin, eds. 2009. Bauhaus Construct: Fashioning Identity, Discourse and Modernism. New York: Routledge.

Scheper, Dirk. 1988. Oskar Schlemmer Das Triadische Ballett und die Bauhausbühne. Berlin: Akademie der Künste.

Simondon, Gilbert. 1969. Du mode d'existence des objets techniques. Paris: Aubier Montagne.

Simondon, Gilbert. 2012. Die Existenweise technischer Objekte. Trans. Michael Cuntz. Zürich: diaphanes. 
Thomas, Lisa May, and Glowacki, David R. 2018. 'Seeing and feeling in VR: bodily perception in the gaps between layered realities.' International Journal of Performance Arts and Digital Media 14 (2): 145-168.

Trimingham, Melissa. 2011. The Theatre of the Bauhaus. London: Routledge.

Tsing, Lowenhaupt Anna (2015) The Mushroom at the End of the World: On the Possibility of Life in Capitalist Ruins. Princeton: Princeton University Press.

William Forsythe: The Fact of Matter. An exhibition at MMK Museum für Moderne Kunst Frankfurt, 17 October 2015 - 13 March 2016.

Won, Andrea Stevenson; Bailenson, Jeremy; Lee, Jimmy; Lanier, Jaron. 2015. 'Homuncular Flexibility in Virtual Reality.' Journal of Computer-Mediated Communication, 20 (3): 241-259.

Zumthor, Peter. 2006. Atmospheres: Architectural Environments - Surrounding Objects. Basel: Birkhäuser Verlag. 